\title{
Early experiences modulate stress coping in a population of German shepherd dogs
}

\author{
Pernilla Foyer, Erik Wilsson, Dominic Wright and Per Jensen
}

\section{Linköping University Post Print}

\section{Tweet}

N.B.: When citing this work, cite the original article.

Original Publication:

Pernilla Foyer, Erik Wilsson, Dominic Wright and Per Jensen, Early experiences modulate stress coping in a population of German shepherd dogs, 2013, Applied Animal Behaviour Science, (146), 1-4, 79-87.

http://dx.doi.org/10.1016/j.applanim.2013.03.013

Copyright: Elsevier

http://www.elsevier.com/

Postprint available at: Linköping University Electronic Press

http://urn.kb.se/resolve?urn=urn:nbn:se:liu:diva-92752 
Early experiences modulate stress coping in a population of German shepherd dogs

Pernilla Foyer ${ }^{1,2}$, Erik Wilsson ${ }^{3}$, Dominic Wright ${ }^{1}$, Per Jensen ${ }^{1 *}$

1IFM Biology, AVIAN Behaviour Genomics and Physiology group, Linköping University 58183 Linköping, Sweden

${ }^{2}$ Department of Military Studies, Military-Technology Division, Swedish National Defence College, 11593 Stockholm, Sweden

3Swedish Armed Forces Dog Instruction Centre, 19524 Märsta, Sweden

${ }^{*}$ Corresponding author at: IFM Biology, AVIAN Behaviour Genomics and Physiology group,

Linköping University, 58183 Linköping, Sweden. Phone +46 13 281298, Fax No. +4613281399.

E-mail address: perje@ifm.liu.se (Per Jensen) 


\section{Abstract}

Early experiences may alter later behavioural expressions in animals and these differences can be consistent through adulthood. In dogs, this may have a profound impact on welfare and working ability and, it is therefore interesting to evaluate how experiences during the first weeks of life contribute to shaping the long-term behaviour. We analysed data from 503 dogs from 105 litters, bred at the Swedish Armed Forces Dog Kennel. For each dog, the data comprised information on dam and sire, sex, litter size, sex ratio of litter, date of birth, and weight at birth, and at 10 days of age. Between the ages of 377 and 593 days, the dogs were tested in a temperament test, assessing their suitability as working dogs. The behaviour test comprised 12 different sub-tests, and was scored on a behavioural rating scale. A principal components analysis showed that the test performance could largely be attributed to four principal components (explaining 55.7\% of variation), labelled Confidence, Physical Engagement, Social Engagement and Aggression. We analysed the effects of the different early life variables and sex on the principal component scores (PC scores) using linear modelling. PC scores on Confidence were affected by parity, sex and litter size, and Physical Engagement was affected by parity, growth rate, litter size and season of birth. Social Engagement was affected by growth rate and sex, and Aggression was affected by sex. Some of these effects disappeared when they were combined into a single linear model, but most of them remained significant also when controlling for collinearity. The results suggest that the early environment of dogs have long-lasting effects on their behaviour and coping styles in a stressful test situation and this knowledge can be used in the work with breeding of future military or police working dogs.

\section{Keywords}

Early experience; Personality; Behaviour; Temperament test; Stress; Working dog 


\section{Introduction}

Studies of personality have been of great interest for decades and the way in which personality is affected by early experiences is an important area of research within applied ethology. Since early experiences may alter the phenotypic, genomic and behavioural expression of the animal, and these differences can be consistent through adulthood, they may also have a profound impact on animal welfare and working ability. Numerous studies focusing on personality in both humans and a wide range of non-human species (Gosling, 2001; Gosling and John, 1999) have been carried out and one of the most accepted models for understanding the relationship between personality and behaviour in humans today is Costa and McCrae's Five Factor Model (FFM) (Costa and McCrae, 1992). Attempts to apply this model on non-human animals have been done with some success on chimpanzees (Weiss et al., 2000) and dogs (Svartberg and Forkman, 2002). The cross-species generality of the FFM also found some support in a review by Gosling and John (1999), where data from 12 different species were analysed.

In altricial, like the dog, species the young are born in a state of neural immaturity. However, the nervous system develops quickly via an intense synaptogenesis, during which external stimuli play an important role (Gazzano et al., 2008). Hence, environmental influences during early postnatal development may have a profound and lasting effect on an animal's later behaviour (Rosenzweig, 1984) and physiology. Not only postnatal environment, but also prenatal environment can cause postnatal effects. For instance, Braastad et al. (1998) have shown that prenatal maternal stress causes postnatal effects on the adrenal function in the offspring of blue foxes and similarly, prenatal stress in rodents can have a long term effect on offspring with respect to behaviour and reproductive functions (Champagne et al., 2003; Chapillon et al., 2002; De Kloet et al., 2005; Kinsley and Bridges, 1988).

The prenatal period therefore, seems to be a potentially important time for lifelong alterations of response patterns, but early postnatal experiences also influence development. In social mammals, the neonatal period is a time of significant social interaction and an important time for development of social behaviour (Cushing and Kramer, 2005), as well 
as the stress response (Liu et al., 1997). During early postnatal development, the mother of most mammals provides the primary environmental cues to her offspring. Champagne et al. (2003) proposed that the mother may be able to modify her young's behaviour adaptively to their future environment by means of the stimuli provided during the immediate postnatal period. Earlier studies have also indicated that specific conditions in the maternal environment, such as litter composition, litter size, previous maternal experiences of the mother as well as other environmental factors (Kikusui et al., 2008) can all affect maternal behaviour and thereby the development of the offspring not only in rodents (Caldji et al., 2000; Champagne and Meaney., 2006; Francis et al., 1999), but also in chickens (Groothuis et al., 2005), rhesus monkeys (Schapiro et al., 1995) and other species. Priestnall (1973) found that female mice rearing large litters spent less time caring for their young and Brown et al. (1999) observed that survival rate and weight gain improved as mothers became more experienced. Likewise, the presence of siblings and the sex ratio within a litter might have long-lasting fitness consequences because they influence the early environment in which the animal develops (Monclus and Blumstein, 2011). Sex ratio and litter size can influence development both before and after birth. For example, in utero placement can have an effect on later development and behaviour due to differences in hormonal environment based upon the sex of neighbouring foetuses. Earlier studies have shown long-lasting effects from the presence of male siblings in utero on morphology and behavioural traits in mice (Quadagno et al., 1987, Ryan and Vandenbergh, 2002), in sheep (Avdi and Driancourt, 1997) and in voles (Galea et al., 1994). Whereas dogs have a different placentation than rodents, it is uncertain but possible that similar effects could affect pups prenatally. Further did Seitz (1954) find that rats raised in small litters reacted with less anxiety and more exploratory behaviours to novel experiences in adulthood than did animals raised in large litters. Likewise large litter size was found to induce more aggressiveness in pigs (D'Eath and Lawrence, 2004).

It can therefore be hypothesised that similar maternal and litter effects exist in dogs, another altricial species, and earlier studies have suggested that such effects may be 
present (Scott and Bielfelt, 1976; Scott and Fuller, 1965; Slabbert and Rasa, 1997; Wilsson and Sundgren, 1998). Other environmental factors such as season of birth have also shown to significantly influence adult behaviour in dogs (van der Waaij et al., 2008). Knowledge of processes like these may add to our understanding of dog behaviour and increase the efficiency of breeding dogs for specific working purposes.

In the present study, records of 503 German shepherd dogs (GSD) from 105 litters bred at the Swedish Armed Forces (SAF) were analysed in order to evaluate how early maternal and litter traits may correlate with different behavioural traits measured in adults. The behavioural traits were extracted from a temperament test used by the SAF. Since the start of the SAF breeding program in 2005 and up till 2010, only $27 \%$ of the dogs have been approved to work as Military Working Dogs (MWD) or within the police force. Most of the rejected dogs have a personality profile, which does not suit the needs of the Armed Forces, but dogs are also rejected for medical reasons. Because of the large number of rejected dogs for behavioural reasons it is of the highest importance to study how early experiences such as maternal and litter effects affect the behaviour of the adult dog.

\section{Material and Methods}

\subsection{Animals and litter variables}

The dogs in this study were all German shepherd dogs bred within the breeding program of the Swedish Armed Forces (SAF) between 2005 and 2010. Bitches were kept at the SAF kennel in Sollefteå only during the whelping and nursing period, and at all other times both the adult breeding animals and the pups, from weaning (at 8 weeks of age) until selection (at 15-18 months of age), were kept in private foster homes situated all over the country.

The bitches arrived at the breeding kennel from their respective foster homes three weeks prior to estimated whelping and left the kennel when the pups were delivered to 
their foster homes at the age of 8-10 weeks. The pups were group-housed with their litter and mother until weaning at eight weeks of age and later stayed in their foster homes until they were called back for physical and temperament testing and evaluation. For each litter, detailed records were obtained on birth date, identities and parents. Pups were weighed every $10^{\text {th }}$ day, and records were kept on the size and composition of each litter. The following variables were obtained for analysis for each individual: Parity (number of litters per bitch), birth weight and growth rate (calculated as the weight at day 20 minus the birth weight), sex, sex ratio (calculated as the number of males divided by the total number of pups in each litter), litter size (number of pups in the litter), season of birth (the year was divided in four periods beginning from January to March, April to June, July to September and October to December). Sex was included in the analysis in spite of not being an environmental effect, since we assumed that sex could interact with the other variables. These were chosen to evaluate which, if any, of the early experiences e.g. early maternal and litter traits that may correlate with different behavioural traits measured in pups as adults.

At the age of 13-14 months pups were x-rayed for hip- and elbow joint dysplasia and around the age of 15 months they were tested in a temperament assessment test (T-test). All dogs included in this study were German shepherd dogs. The material consists of 722 dogs. 96 dogs were excluded for medical reasons and 123 for incomplete tests, leaving 503 with complete records to be analysed ( $\mathrm{N}$ males $=254 ; \mathrm{N}$ females $=249$ ). The average test age was 489.3 days ( $\mathrm{SD}=31.2$ days) from a range between 377 to 593 days. Only dogs that passed both the medical evaluation and the temperament test were put into training.

\subsection{General test procedure}

The T-test used by the SAF, which has recently been described by Wilsson and Sinn (2012), consists of a modified version of the Dog Mentality Assessment test (DMA) described by Svartberg and Forkman (2002). The purpose of the T-test was to describe the behaviour in 12 
different sub-test situations and was used as a tool in evaluating if the dog was suitable to put through training as a future MWD. All the dogs were tested in one out of five test locations in Sweden: Ronneby, Göteborg, Märsta, Sollefteå and Luleå. One single trained observer recorded all test outcomes in order to avoid judgement bias.

The 12 standardized sub-tests were performed in the same specific order by all

dogs. All sub-tests were carried out consecutively and without breaks, except for the time it took to move from one sub-test station to another (less than one minute); the sub-tests combined take on average $40 \mathrm{~min}$. to complete. Behaviour tests were always performed between 08:00 $\mathrm{h}$ and 16:00 $\mathrm{h}$. The handler, usually a person from the foster home, accompanied the dog during the whole test, except for the subtest Darkness, in which the handler entered the room before the dog. A trained test leader was responsible for the practical aspects of the test and instructed the handler how to act and guided the handler and subject dog through the different sub-tests. Only dogs with a complete score sheet were used in statistical analyses in this study.

\subsection{Behavioural rating}

The 12 different sub-test situations were rated on a total of 25 variables. All subject dogs were described according to two different protocols, Subjective rating (SR) that was based on the observer's overall perception of the dog's aggregated behavioural disposition during the whole T-test, and Behavioural rating (BR) that described the dog's reactions in predefined intensity levels, from 1 (low intensity/expression of trait) to 5 (high intensity/expression of trait). In this study only the BR data were analysed. The predefined scales in the BR protocol were as far as possible free from subjective opinions, and were listed on a standardized score sheet used to record the dog's reactions. The sub-tests and the behavioural variables are described in detail in Wilson and Sinn (2012) . Generally the tests consisted of 12 different standardized test situations where some measured the reaction to potentially frightening stimuli of different kinds, some measured the response to contact with unknown humans and some investigated 
environmental cues. The first three sub-tests are called Affability (the dog is greeting a number of unknown persons), Handling (the dog is handled by an unknown person, the test leader, TL) and Leash (the dog is taken on a short walk with the TL) and are intended to measure and describe the dog's reaction to unfamiliar persons. The next three, called Tug-of-War (the TL invites the dog to a tug-of-war with a cotton rag), Chasing and Interest in object (the TL rolls a tennis ball, which the dog is allowed to chase and retrieve), measure play intensity and play interest. This is followed by three sub-test situations intended to measure and describe the dog's reaction in different environmental contexts. These are called Reaction in dark room (the dog enters a dark room in which the handler is hiding), Metal stair (the dog, on leash, walks up and down a steep metal stair) and Reaction on table (the dog is asked to jump up on a wobbling table approximately $60 \mathrm{~cm}$ high, that can be displaced $2-3 \mathrm{~cm}$. The TL offers the dog a tennis ball, while the table is still moving). Then follows three different sub-test situations that intend to measure and describe the reactions to potentially frightening stimuli; Acoustic (while the dog is being walked on leash by the handler a pair of steel buckets is dropped on the floor approximately $2 \mathrm{~m}$ from the dog), Visual (when the dog is walking on leash with handler a pair of life-sized coveralls is pulled into the air by the TL, resulting in the shape of an ' $\mathrm{X}$ ', two meters in front of the dog) and Gradual visual (a paper figure, mounted on two wooden planks, is slowly moved toward the dog and stopped at $3 \mathrm{~m}$ distance from the $\mathrm{dog}$ ). This is followed by a sub-test that measures and describes the dog's Search intensity and persistence (a tennis ball is rolled towards the TL, who hides the ball under a wooden pallet. When the ball has been hidden the dog is released and allowed to independently search for the ball). The test ends with the sub-test Gunfire (two, 9-mm blank shots are fired from $25 \mathrm{~m}$ away out of the visual sight of the subject.). The last sub-test was not included in present analysis, since the behaviour of the dogs showed no correlation to any other test variable, and therefore probably reflects a very specific fear reaction. 


\section{Statistical analysis}

The scores of all behavioural variables were subjected to a principal component analysis (PCA) without rotation. This method was used for data reduction, in order to produce a small number of uncorrelated component scores for each individual, without any assumptions of any underlying latent structure. Hence, no rotation of the resulting component structure was done. Based on the PCA, PC scores were calculated for each individual. We then analysed the effects of season, maternal effects and litter effects on the scores obtained, using a two-step analysis. First, we tested the effect of each of the independent variables singly on the PC score in a linear model. Thereafter, we constructed a second, linear model where we fitted all the variables that had reached a P-value larger than 0.1 in the same model, and calculated new F and P-values for each independent variable, while taking other significant ones into account. In this way, we were able to sort out the potentially important variables, and then control for collinearity. For the analysis, we used R and SPSS (version 20). 


\section{Results}

\subsection{Behaviour in the T-test}

The PCA revealed six underlying PCs with eigenvalues $>1$ that together explained $66.8 \%$ of the total variance. All but three behavioural variables (Gun shot fear, Gun shot interest and Liveliness) had communalities above 0.5 and were retained for further analysis. Based on eigenvalues and the shape of the scree plot, we decided to further evaluate and label the four first PCs, which together explained $55.7 \%$ of the variance. The criterion for further considering the relevance of a variable loading on a particular PC was set to a loading of $>0.5$ and 19 of the 23 remaining behavioural variables fulfilled this criterion for at least one of the four first PCs (Table 1).

The first PC explained 28.3\% of variance and had strong loadings from 15 behavioural variables (Table 1). This PC was spanned primarily by behavioural variables that reflected general activity and responses in startling situations and was therefore labelled Confidence. Two of the behavioural variables (Chasing and Interest in object) also loaded high on the second PC. The second PC was labelled Physical Engagement and the third PC that had high loadings for the variables Handling and Affability was labelled Social Engagement based on the variables spanning it. The fourth PC had high loadings only for aggression and was therefore labelled Aggression. The loadings of each variable and the PC labels are given in Table 1.

\subsection{Maternal, litter and seasonal effects}

The PC scores were significantly affected by several of the maternal, litter and seasonal variables recorded when they were considered singly. A few of the significant effects disappeared when the combined linear model was used, but most of them remained at a P-value, which was at the same level as for the single factor model. Summaries of the results are found in Table 2 and in 
Fig. 1 and Fig. 2. It is obvious that some of the effects are of a rather small magnitude, which is what could be expected given the fact that the dogs were kept in host families for more than a year before the test. During that period, there was no control of their experiences, and it is therefore quite striking that the early life experiences are still detectable in the present analysis. The parity of the bitch had a significant effect on the scores on the PCs Confidence and Physical Engagement, and both effects remained in the combined model. Even though the Confidence score seemed to drop with the second litter, there was a substantial increase by the third litter, and Physical Engagement score increased with increasing litter number.

Birth weight only showed a trend for effect on Physical Engagement, and this effect disappeared in the combined model, while Growth rate showed significant effects on both Physical Engagement and Social Engagement scores in both models. Dogs with high weights and higher growth rates scored higher on Physical Engagement, and higher growth rates were associated with higher Social Engagement scores.

The sex of the dog significantly affected the scores on Confidence, Social Engagement and Aggression. The effects were moderately weaker in the combined model, where the effects on Confidence and Aggression decreased to a tendency $(\mathrm{P}<0.1)$. Females scored lower than males on Confidence and Aggression, but higher for PC Social Engagement.

The sex ratio of the litter tended to affect Aggression scores in a single, but not the combined model, and the direction of the weak tendency was not obvious from the results.

There were tendencies for effects of litter size on Confidence and Physical Engagement scores in the single model, but in the combined model, only the tendency for effects on Confidence remained. Dogs born in small litters tended to have higher Confidence scores, but there were no obvious direction for the effect on Physical Engagement.

Season of birth significantly affected the Physical Engagement score, and tended to affect the Social Engagement and Aggression scores, in the single variable model. In the combined model, only the effect on Physical Engagement remained. The Physical Engagement score was lower in litters born during the summer months, while the Social Engagement score 
appeared lower in litters born during the winter months. Aggression scores tended to be highest in litters born during January to March and lowest during October to December. There was also a significant effect of the Season during which the tests were performed on Social Engagement scores in both models, with the lowest scores in litters born from April to June and the highest during July to September.

\section{Discussion}

The results from this study suggest that the early environment of dogs has long-lasting effects on their behaviour in a stressful test situation encountered as adults. The reactions formed a set of coherent personality traits, similar to those recently demonstrated by Wilsson and Sinn (2012). The dogs' scores on the different personality dimensions (PC-scores) were significantly affected by parity, growth rate, sex, litter size and the season of birth. The results of the study therefore demonstrate that long-term modifications of the way in which dogs react to stressful stimuli are partly shaped by their experiences during the first weeks of life.

In this study we aimed to characterise the effects of early experiences on the reaction patterns of dogs in a stressful test situation, possibly reflecting distinct personality traits. Personality can be defined as a unique, dynamic and organized set of characteristics possessed by an individual and that influences its cognition, motivations, emotions, and behaviours in various situations (Ryckman, 2004). Many of these behavioural traits have also been found to be consistent across time and situations (Svartberg et al., 2005) in dogs. In order to study personality, one needs to measure a range of different operational behavioural variables, thought to reflect the underlying personality dimensions. The results from the PCA in this study revealed six PCs with eigenvalues >1.0, out of which four were labelled, "Confidence", "Physical Engagement", “Social Engagement” and "Aggression”. Although the components were more complex than indicated by the labels, they clearly demonstrate that the reactions of the 
dogs formed coherent structures of correlated behaviour patterns across the subtests, even if the exact motivational background of each of these is beyond the scope of the present study. However, a very similar structure was observed also by Wilsson and Sinn (2012), based on largely the same data as in this study, but using a somewhat different statistical analysis. This indicates that the PC-solution in the present study may actually reflect an underlying personality profile of the dogs. The first PC strongly resembles the personality factor "Boldness", a common dimension in many previous behavioural studies (Wilson et al., 1994). The shyness-boldness axis, which is a fundamental dimension in human personality, can be defined as the general tendency to approach a novel object and willingness to take risks (Wilson et al., 1994). The shyness-boldness dimension has earlier been detected in a variety of different species such as fish (Sneddon, 2003), birds (Carere and van Oers, 2004), squid (Sinn and Moltschaniwskyj, 2005), cats (Feaver et al., 1986) and dogs (Svartberg and Forkman, 2002) among others.

The remaining PCs, labelled Physical Engagement, Social Engagement and Aggression, are also similar to typical personality dimensions observed in studies of dogs and other mammals (Gosling, 1999). This indicates that the temperament test used in this study, although being a quick and rather crude behavioural assessment, actually captures important aspects of dog personality. However, it should be remembered that the test was not specifically designed for a broad characterisation of dog behaviour, but rather to provide guidance in selecting dogs suitable for military or police training. Hence, there is a bias in the test towards exposing dogs to threatening, frightening and stressful stimuli, which is what a suitable working dog needs to be able to cope with. This also means that the test in effect could be regarded as primarily a stress test, and the reactions of the dogs may therefore chiefly reflect different coping styles more than general personality types. Koolhaas (1999) characterised two main coping styles in animals. The first one, the proactive, is behaviourally characterized by territorial control and aggression and corresponds to what was originally described by Cannon (1915) as the fight-flight response. The second, reactive style, was originally described by Engel and 
Schmale (1972) as the conservation-withdrawal response and is behaviourally characterised by immobility and low levels of aggression.

In determining the effects of early experiences on the behaviour test results, we selected a number of variables, which we believed would reflect both the qualities of the maternal behaviour and environmental challenges. The parity of the mother was chosen as an indicator of experience, where more experienced bitches could be assumed to provide more mature maternal behaviour. Birth weight and growth rate were chosen to represent the early maternal investment of the mothers. Large pups had received more investment during the foetal stage, and pups with a high early growth rate (up to 20 days) are assumed to have been fed more milk by their mothers. Effects of litter sex ratio could reflect both hormonal influences during the foetal life, and post-partum effects caused by sex related behaviour differences in the littermates. Season of birth could affect the dogs through a variety of pathways: temperature in the birth room may be lower, and the bitch may have been affected by low temperature during pregnancy and lactation. Lower temperature may also have caused the bitch to increase her efforts to care for the pups. It is not within the scope of the present study to determine the actual causes of the effects found, nor is it to analyse how the environmental factors co-vary. However, the two-step statistical analysis was carried out as an attempt to disentangle true effects of a single variable from collinear effects. The fact that most of the examined effects did not show a substantial difference in P-values between the models indicates that several early life factors affected the later performance of the dog independently.

In this study the variable Parity affected PC scores for Confidence and Physical Engagement, but not Social Engagement or Aggression. Hence, more experienced mothers may have modified the coping styles of the dogs. On the other hand the bitches that were chosen in this breeding program to have more than one litter should be considered a selected group based on result of former litters, since poor performers were usually excluded from further breeding. Growth rate showed weak but significant results for both Physical Engagement and Social 
Engagement, while Birth weight showed a tendency for Physical Engagement, but only when analysed in a single variable model, again demonstrating that the degree of maternal investment modified the later behaviour of the offspring. Wilson and Sundgren (1998) found that large female pups were more active and explorative in a puppy test and scored significantly higher for defensive drive and hardness as adults.

In this study the sex of the dog affected Confidence, Social Engagement and Aggression, and the effects remained significant or decreased to a tendency in the combined model, whilst a weak sex ratio effect on Aggression disappeared in the combined model. Hence, sex, but not litter sex ratio, was an important factor in determining reactions in the behaviour test. In other species, the sex effect is not always obvious. For example, sex did not affect aggression in pigs (D'Eath and Lawrence, 2004), while sex ratio on the other hand (Crews et al., 2009; Mendl and Paul, 1990; Namikas and Wehmer, 1978) clearly affects aggression at least in rodents. However, aggression in the later studies was tested using conspecifics in a standard resident intruder test and in this study, aggression was measured as a response to a threatening event. It is therefore likely that what we label as Aggression is not related to intra-specific aggression, and could perhaps better reflect the traits sharpness or defence drive as defined by Wilsson and Sundgren (1997). It is also possible that it is wrong to draw this simplistic comparison about aggression due to in utero hormonal effects because of differences in placentation patterns among different mammalian species.

Litter size tended to affect Confidence and Physical Engagement, but the effects vanished in the combined model, indicating that litter size in itself may not have been an important factor in determining the later test reactions. However, Seitz (1954) found that rats raised in small litters were less anxious and more explorative as adults in novel situations compared to rats raised in large litters, and further have pigs been shown to be more aggressive if they are born in larger litters (D'Eath and Lawrence, 2004), effects which could not be confirmed in the dogs in the present study. 
Season of birth significantly affected Physical Engagement, while the tendencies for effects on Social Engagement and Aggression were not present in the combined models. van der Waaij et al. (2008) found significant effects of Season of births between March and August on prey drive, defence drive and courage in GSD and suggested that this may be due to fluctuations in hours of daylight and correlated fluctuations in serotonin and dopamine levels, or that the variation in behavioural traits in dogs are related to the reproduction cycle.

Not only the early environmental factors assessed here will most likely affect the temperamental development of the dogs. Events in the dog's lives in their foster homes, from the age of 8 weeks till the test is performed, can naturally also play a part but those effects are out of the scope of this study.

\section{Conclusions}

The present results show that the early environment of dogs has long-lasting effects on their behaviour and coping styles in a stressful test situation. The mechanisms involved in this are however at present unknown, but the dogs' reaction patterns in a test conducted at about 15 months of age formed a set of coherent personality traits, which were significantly affected by some of the maternal, litter and seasonal variables experienced early in life. The results of our study therefore demonstrate that the dogs' experiences during the first weeks of life partly cause life-long modifications in the way in which they react to stressful stimuli.

\section{Acknowledgements}

We would like to thank the Swedish Armed Forces Dog Instruction Centre for permitting us to use the data record and test results of their dogs. The study was performed within the framework of the Swedish National Defence Collage doctoral program and the Swedish Centre of Excellence in Animal Welfare Science, who are financed by the research council, Formas. 
Avdi, M., Driancourt, M.A., 1997. Influence of sex ratio during multiple pregnancies on productive and reproductive parameters of lambs and ewes. Reprod. Nutr. Dev. 37, 21-27.

Braastad, B.O., Osaduchuk, L.V., Lund, G., Bakken, M., 1998. Effects of prenatal handling stress on adrenal weight and function and behaviour in novel situations in blue fox cubs (Alopex lagopus). Appl. Anim. Behav. Sci. 57, 157-169.

Brown, R.E., Mathieson, W.B., Stapleton, J., Neumann, P.E., 1999. Maternal Behavior in Female C57BL/6J and DBA/2J Inbred Mice. Physiol. Behav. 67, 599-605.

Caldji, C., Diorio, J., Meaney, M.J., 2000. Variations in maternal care in infancy regulate the development of stress reactivity. Biol. Psychiat. 48, 1164-1174.

Cannon, W.B., 1915. Bodily Changes in Pain, Hunger, Fear and Rage: an account of recent researchers into the function of emotional excitement. D. Appleton and Company. New York.

Carere, C., van Oers, K., 2004. Shyness and Boldness in great tits (Parus major): body temperature and breath rate in response to handeling stress. Physiol. Behav. 82, 905-912.

Champagne, F.A., Francis, D.D., Mar, A., Meaney, M.J., 2003. Variations in maternal care in the rat as a mediating influence for the effects of environment on development. Physiol. Behav. 79, 359-371.

Champagne, F.A., Meaney, M.J., 2006. Stress During Gestration Alters Postpartum Maternal Care and the Development of the Offspring in a Rodent Model. Biol. Psychiat. 59, 1227-1235. 
Chapillon, P., Patin, V., Roy, V., Vincent, A., Caston, J., 2002. Effects of pre- and postnatal stimulation on developmental, emotional, and cognitive aspects in rodents: A review. Dev. Psychobiol. 41, 373-387.

Costa, P.T. Jr., McCrae, R.R., 1992. NEO-PI-R: Professional Manual.

Crews, D., Rushworth, D., Gonzalez-Lima, F., Ogawa, S., 2009. Litter environment affects behavior and brain metabolic activity of adult knockout mice. Front. Behav. Neurosci. 3, 12.

Cushing, B.S., Kramer, K.M., 2005. Mechanisms underlying epigenetic effects of early social experience: The role of neuropeptides and steroids. Neurosci. Biobehav. R. 29, 1089-1105.

D'Eath, R., Lawrence, A.B., 2004. Early life predictors of the developpment of aggressive behaviour in the domestic pig. Anim. Behav. 67, 501-509.

de Kloet, R.E., Sibug, R.M., Helmerhorst, F.M., Schmidt, M., 2005. Stress, genes and the mechanism of programming the brain for later life. Neurosci. Biobehav. R. 29, 271281.

Engel, G.L., Schmale, A.H., 1972. Conservation-withdrawl: a primary regulatory process for organismic homeostasis In Ciba Foundation Symposium 8 - Physiology, Emotion and Psychosomatic Illness ed. R Porter, J Knight

Feaver, J., Mendl, M., Bateson, P., 1986. A method for rating the individual distinctiveness of domestic cats. Anim. Behav. 34, 1016-1025.

Francis, D., Diorio, J., Liu, D., Meaney, M.J., 1999. Nongenomic transmission Across generation of Maternal Behaviour and Stress Responses in the Rat. Science. 286, 1155. 
Galea, L.A., Ossenkopp, K.P., Kavaliers, M., 1994. Performance (re-acquisition) of a watermaze task by adult meadow voles: effects of age of initial task acquisition and in utero environment (litter sex-ratio). Behav. Brain. Res. 63, 177-185.

Gazzano, A., Mariti, C., Notari, L., Sighieri, C., McBride, E.A., 2008. Effects of early gentling and early environment on emotional development of puppies. Appl. Anim. Behav. Sci. $110,294-304$.

Gosling, S., 2001. From mice to Men: What can we learn about Personality From Animal Research? Psychol. Bull. 127, 45-86.

Gosling, S., John, O., 1999. Personality Dimensions in Nonhuman Animals: A Crossspecies Review. Curr. Dir. Psychol. Sci. 8, 69-75.

Groothuis, T.G.G., Müller, W., von Engelhardt, N., Carere, C., Eising, C., 2005. Maternal hormones as a tool to adjust offspring phenotype in avian species. Neurosci. Biobehav. R. 29, 329-352.

Kikusui, T., Nakamura, K., Mori, Y., 2008. A review of the behavioral and neurochemical consequences of early weaning in rodents. Appl. Anim. Behav. Sci. 110, 73-83.

Kinsley, C.H., Bridges, R.S., 1988. Prenatal stess and maternal behaviour in intact virgin rats: response latencies are decreased in males and increased in females. Horm. Behav. 22, 76-89.

Koolhaas, J.M., Korte, S.M., De Boer, S.F., Van Der Vegt, B.J., Van Reenen, C.G., Hopster, H., De Jong, I.C., Ruis, M.A.W., Blockhuis, H.J., 1999. Coping styles in animals: current status in behavior and stress-physiology. Neurosci. Biobehav. R. 23, 925-935.

Liu, D., Diorio, J., Tannenbaum, B., Caldji, C., Francis, D., Freedman, A., Sharma, S., Pearson, D., Plotsky, P.M., Meaney, M.J., 1997. Maternal care, Hippocampal Glucocorticoid Receptors and Hypothalamic-Pituitary-Adrenal responses to Stress. Science. 277, 1659. 
Mendl, M., Paul, E.S., 1990. Litter composition affects parental care, offspring growth and the development of aggressive behaviour in the wild house mice. Behaviour 116: 90108

Monclus, R., Blumstein, D.T., 2012. Litter sex composition affects life-history traits in yellow-bellied marmots. J. Anim. Ecol. 81, 80-86.

Namikas, J., Wehmer, F., 1978. Gender composition of the litter affects behavior of male mice. Behav. Biol. 23, 219-224.

Priestnall, R., 1973. Effects of handling on maternal behaviour in the mouse (Mus musculus): an observational study. Anim. Behav. 21, 383-386.

Quadagno, D.M., McQuitty, C., McKee, J., Koelliker, L., Wolfe, G., Johnson, D.C., 1987. The effects of intrauterine position on competition and behavior in the mouse. Physiol. Behav. 41, 639-642.

Rosenzweig, M.R., 1984. Experience, memory, and the brain. Am. Psychol., 39, 365-376.

Ryan, B.C., Vandenbergh, J.G., 2002. Intrauterine position effects. Neurosci. Biobehav. R. $26,665-678$.

Ryckman, R.M., 2004. Theories of Personality. Thomson/Wadesworth. Belmont, CA. Schapiro, S.J., Bloomsmith, M.A., Suarez, S.A., Porter, L.M., 1995. Maternal behavior of primiparous rhesus monkeys: effects of limited social restriction and inanimate environmental enrichment. Appl. Anim. Behav. Sci. 45, 139-149.

Scott, J.P., Bielfelt, S., 1976. Analysis of the puppy-testing program In Guide Dogs for the Blind: Their Selection, Development, and Training, ed. Pfaffenberger, C.J. pp. 39-76. Elsevier, Amsterdam.

Scott, J.P., Fuller, J.L., 1965. Genetics and the Social Behavior of the Dog. University of Chicago Press. Chicago. 
Seitz, P.F., 1954. The effects of infantile experiences upon adult behavior in animal subjects. I. Effects of litter size during infancy upon adult behavior in the rat. Am. J. Psychiat. 110, 916-927.

Sinn, D.L., Moltschaniwskyj, N.A., 2005. Personality traits in dumpling squid (Euprymna tasmanica): context-specific traits and their correlation with biological characteristics. J. Comp. Psychol. 119, 99-110.

Slabbert, J.M., Rasa, A.E., 1997. Observational learning of an acquired maternal behaviour pattern by working dog pups: an alternative training method? Appl. Anim. Behav. Sci. 53, 309-316.

Sneddon, L.U., 2003. The Bold and the Shy: individual differences in rainbow trout. J. Fish. Biol. 9, 442-446.

Svartberg, K., Forkman, B., 2002. Personality traits in the domestic dog (Canis familaris). Appl. Anim. Behav. Sci. 79, 133-155.

Svartberg, K., Tapper, I., Temrin, H., Radesäter, T., Thorman, S., 2005. Consistency of personality traits in dogs. Anim. Behav. 69, 283-291.

van der Waaij, E.H., Wilsson, E., Strandberg, E., 2008. Genetic analysis of results of Swedish behaviour test on German Shepherd Dogs and Labrador Retrievers. J. Anim. Sci. 86, 2853-2861.

Weiss, A., King, J.E., Figueredo, A.J., 2000. The heritability of personality factors in chimpanzees (Pan troglodytes). Behav. Genet. 30, 213-221.

Wilson, D.S., Clark, A.B., Coleman, K., Dearstyne, T., 1994. Shyness and Boldness in humans and other animals. Trends. Ecol. Evol. 9, 442-446.

Wilsson, E., Sinn, D., 2012. Are there differences between behavioral measurement methods? A comparsion of the predictive validity of two rating methods i a working dog program. Appl. Anim. Behav. Sci. 141, 158-172. 
Wilsson, E., Sundgren, P-E., 1997. The use of a behaviour test for selection of dogs for service and breeding I: Methods of testing and evaluating test results in the adult dog, demands on different kinds of service dogs, sex and breed differances. Appl. Anim. Behav. Sci. 53, 279-295.

Wilsson, E., Sundgren, P-E., 1998. Effects of weight and litter size and parity of mother on the behaviour of the puppy and the adult dog. Appl. Anim. Behav. Sci. 56, 245254. 
Table 1.

Results from the Principal Component Analysis showing the behavioural variables with eigenvalues $>1$. The behavioural variables were obtained from the 12 different sub-tests described in Material and Methods, and a full description of each of the variables can be found in Wilsson and Sinn (2012). The table shows the loadings of each variable on each of the four retained components, labelled according to the most salient variables. Loadings over 0.5 are shown in bold. $A$ = Acoustic startle sub-test; V = Visual startle sub-test; G Gradual visual startle sub-test. The total variance explained by the four factors is $55.7 \%$.

\begin{tabular}{|c|c|c|c|c|}
\hline \multirow[b]{3}{*}{ Behavioural variables } & \multicolumn{4}{|c|}{ Principal Component } \\
\hline & Confidence & Physical & Social Engagement & Aggression \\
\hline & & Engagement & & \\
\hline Affability & 0.27 & 0.41 & 0.52 & -0.08 \\
\hline Handling & 0.32 & 0.43 & 0.60 & -0.10 \\
\hline Leash & 0.42 & 0.48 & 0.38 & -0.01 \\
\hline Tug-of-war & 0.57 & 0.46 & -0.11 & 0.12 \\
\hline Chasing & 0.59 & 0.54 & -0.11 & 0.07 \\
\hline Interest in object & 0.58 & 0.51 & -0.11 & 0.07 \\
\hline Reaction in dark room & 0.40 & -0.03 & -0.23 & -0.03 \\
\hline Metal stair & 0.40 & 0.10 & -0.31 & -0.19 \\
\hline Reaction on table & 0.50 & 0.07 & -0.37 & -0.25 \\
\hline Object & 0.61 & 0.32 & -0.29 & -0.12 \\
\hline A. Flight distance & 0.61 & -0.29 & -0.28 & -0.29 \\
\hline A. Secondary response & 0.49 & -0.33 & -0.25 & -0.37 \\
\hline A. Lasting effect & 0.57 & -0.39 & -0.10 & -0.33 \\
\hline V. Flight distance & 0.53 & -0.46 & 0.28 & -0.04 \\
\hline V. Aggression & 0.07 & -0.11 & -0.32 & 0.62 \\
\hline V. Secondary response & 0.57 & -0.34 & 0.39 & 0.03 \\
\hline V. Lasting effect & 0.66 & -0.43 & 0.26 & -0.05 \\
\hline G. Fearfulness & 0.61 & -0.28 & 0.15 & 0.43 \\
\hline G. Aggression & 0.33 & -0.25 & -0.16 & 0.69 \\
\hline G. Secondary response & 0.60 & -0.25 & 0.26 & 0.10 \\
\hline G. Lasting effect & 0.66 & -0.39 & 0.18 & 0.02 \\
\hline Search intensity & 0.69 & 0.29 & -0.15 & 0.11 \\
\hline Search Persistence & 0.69 & 0.24 & -0.15 & 0.12 \\
\hline$\%$ variance explained & 26.9 & 12.1 & 8.3 & 6.9 \\
\hline
\end{tabular}


Table 2.

Outcome of the linear model analysis of the effects of Maternal, Litter and Seasonal variables on the scores on the four principal components Confidence, Physical Engagement, Social Engagement and Aggression. For each effect, the F- and P-values are shown both for the model where the effect has been tested in a single variable model, and the corresponding values for the effect when all variables with P-value less than 0.1 are included in a combined model.

\begin{tabular}{|c|c|c|c|c|c|c|c|c|c|}
\hline \multirow[t]{2}{*}{ Effect } & \multirow[t]{2}{*}{ Model } & \multicolumn{4}{|c|}{$\begin{array}{c}\text { Physical } \\
\text { Engagement }\end{array}$} & \multicolumn{2}{|c|}{$\begin{array}{c}\text { Social } \\
\text { Engagement }\end{array}$} & \multicolumn{2}{|c|}{ Aggression } \\
\hline & & $\mathrm{F}$ & $P$ & $\mathrm{~F}$ & $P$ & $\mathrm{~F}$ & $\mathrm{P}$ & $\mathrm{F}$ & $\mathrm{P}$ \\
\hline \multirow[t]{2}{*}{ Parity } & Single & 11.70 & $<0.001$ & 5.27 & 0.0054 & 1.3 & $>0.1$ & 0.93 & $>0.1$ \\
\hline & Combined & 11.80 & $<0.001$ & 3.55 & 0.029 & & & & \\
\hline \multirow[t]{2}{*}{ Birth weight } & Single & 1.03 & $>0.1$ & 3.84 & 0.051 & 1.18 & $>0.1$ & 0.0002 & $>0.1$ \\
\hline & Combined & & & 0,26 & $>0.1$ & & & & \\
\hline \multirow[t]{2}{*}{ Growth rate } & Single & 0.004 & $>0.1$ & 10.11 & 0.0016 & 5.45 & 0.02 & 0,92 & $>0.1$ \\
\hline & Combined & & & 10.41 & 0.0013 & 5.55 & 0.019 & & \\
\hline \multirow[t]{2}{*}{ Sex } & Single & 4.02 & 0.045 & 0.22 & $>0.1$ & 3.92 & 0.048 & 4.56 & 0.033 \\
\hline & Combined & 3.39 & 0.066 & & & 4.17 & 0.042 & 2.83 & 0.093 \\
\hline \multirow[t]{2}{*}{ Sex ratio } & Single & 1.97 & $>0.1$ & 0,15 & $>0.1$ & 1.61 & $>0.1$ & 2.83 & 0.093 \\
\hline & Combined & & & & & & & 0.80 & $>0.1$ \\
\hline \multirow[t]{2}{*}{ Litter size } & Single & 2.99 & 0.084 & 2.52 & $>0.1$ & 3.69 & 0.055 & 1.84 & $>0.1$ \\
\hline & Combined & 2.9 & 0.09 & & & 0.28 & $>0.1$ & & \\
\hline \multirow[t]{2}{*}{ Season of birth } & Single & 0.82 & $>0.1$ & 6.29 & $>0.001$ & 2.37 & 0.07 & 2.22 & 0.085 \\
\hline & Combined & & & 4.22 & 0.006 & 2.04 & $>0.1$ & 1.99 & $>0.1$ \\
\hline
\end{tabular}


Fig. 1. Mean scores (+/- SEM) of Confidence, Physical Engagement, Social Engagement and Aggression for each level of the variables Parity (a-d), Sex (e-h), Litter size (i-l), Season of birth (m-p).

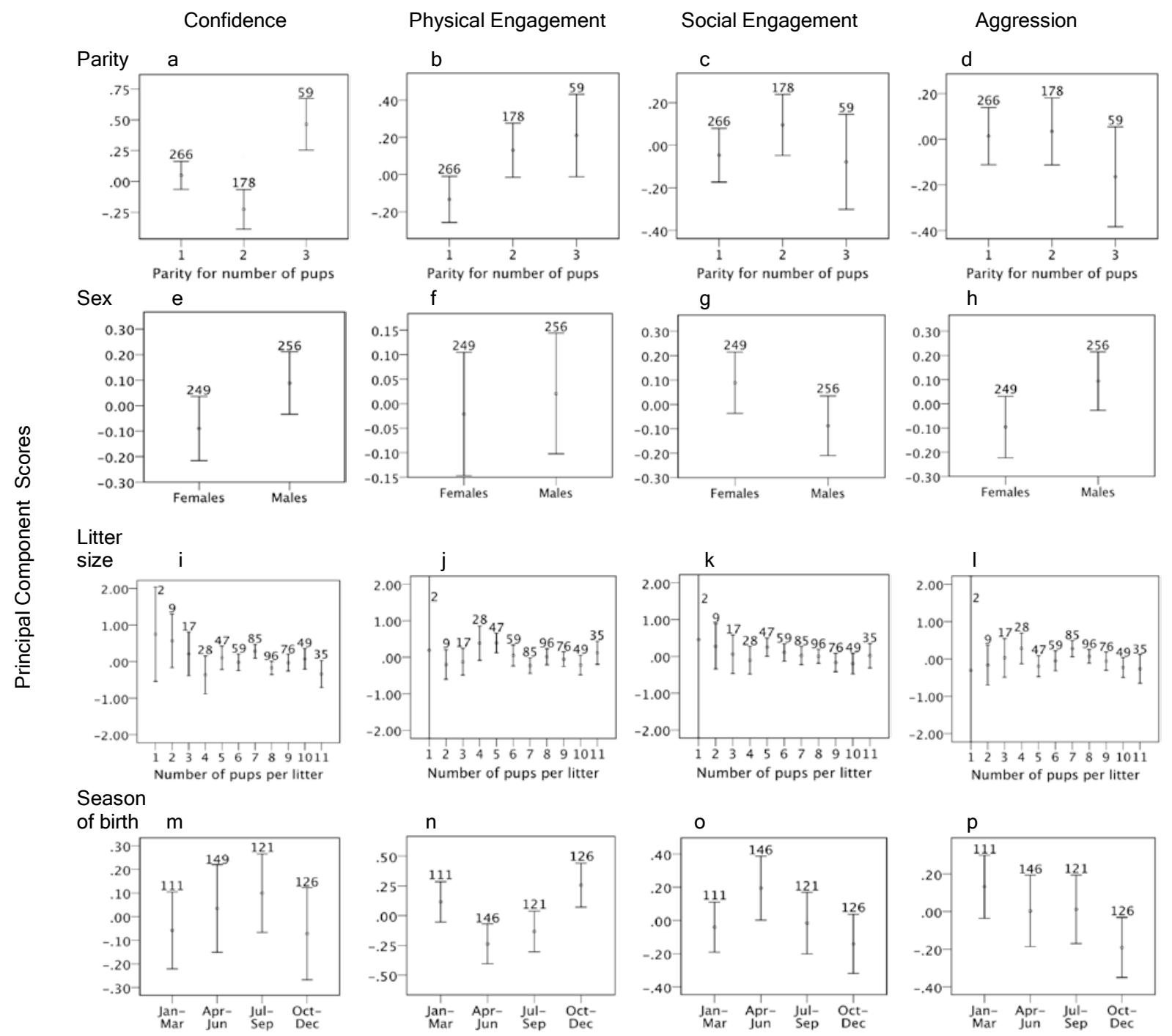


Fig. 2. Scatter plot of individual PC scores for Confidence, Physical Engagement, Social

Engagement and Aggression plotted against the continuous variables Sex ratio (a-d), Birth weight (e-h) and Growth rate (i-l). N=504.

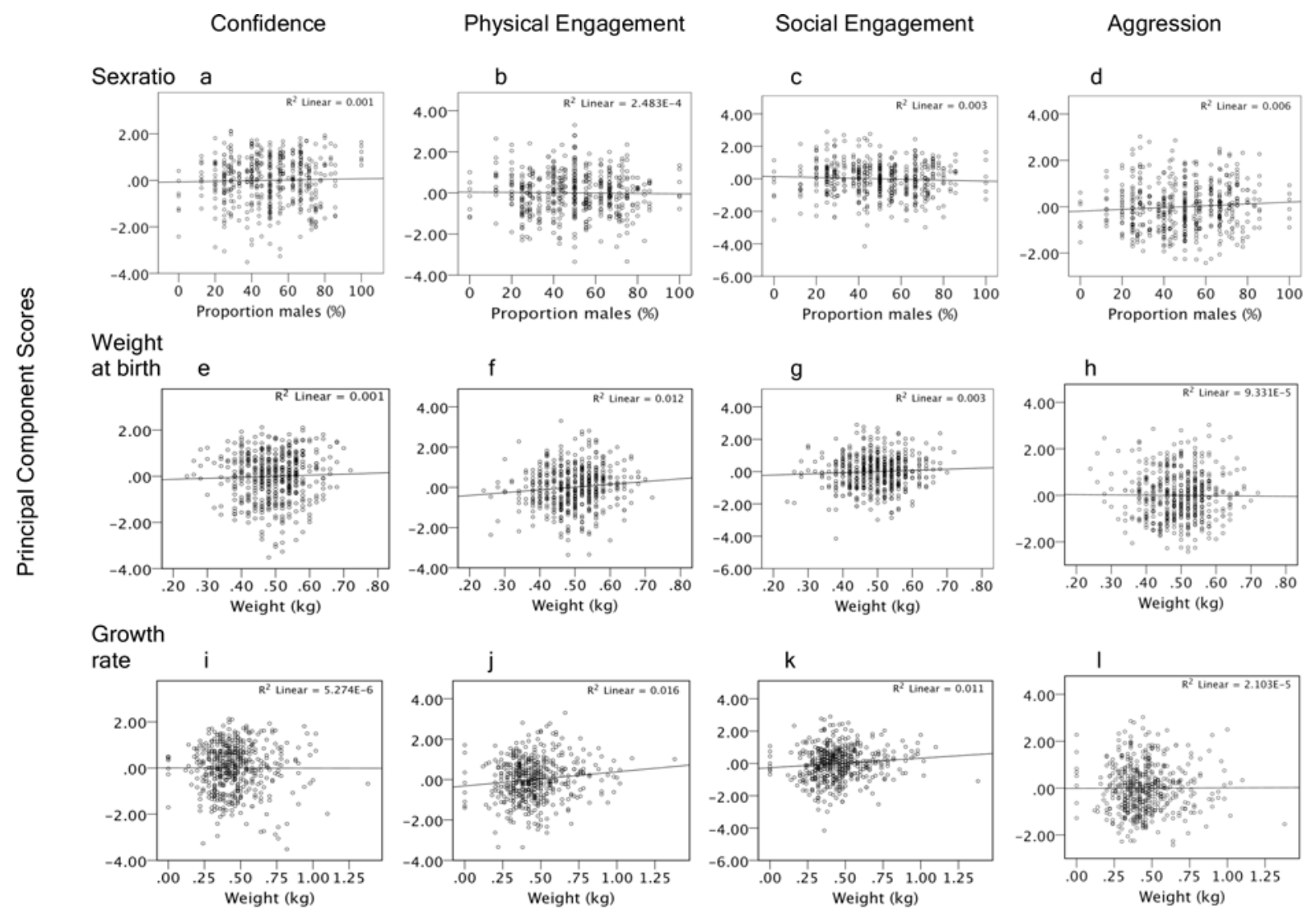

